\title{
A fatal case of a colonic fistula communicating with a walled-off area of pancreatic necrosis
}

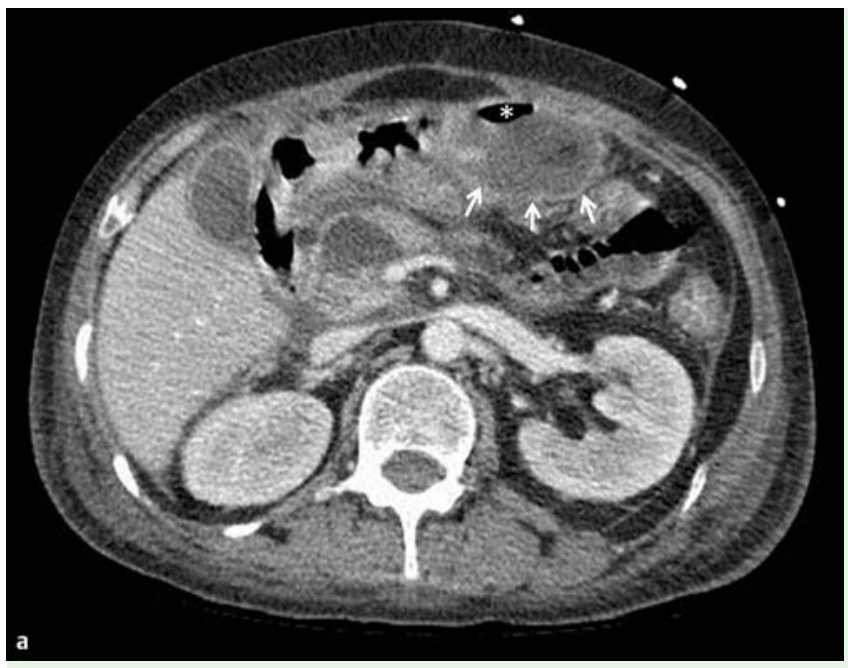

Fig. 1 Computed tomography (CT) scan of the upper abdomen in a 28-year-old woman with chronic glomerulonephritis, pneumonia, and acute necrotizing pancreatitis showing: a a walled-off area of necrosis in the pancreas (arrows) containing an air bubble $\left({ }^{*}\right)$ in axial view; $\mathbf{b}$ a walled-off area of necrosis in the transverse mesocolon $\left({ }^{*}\right)$ with pressure effect on the transverse colon (arrows) in coronal

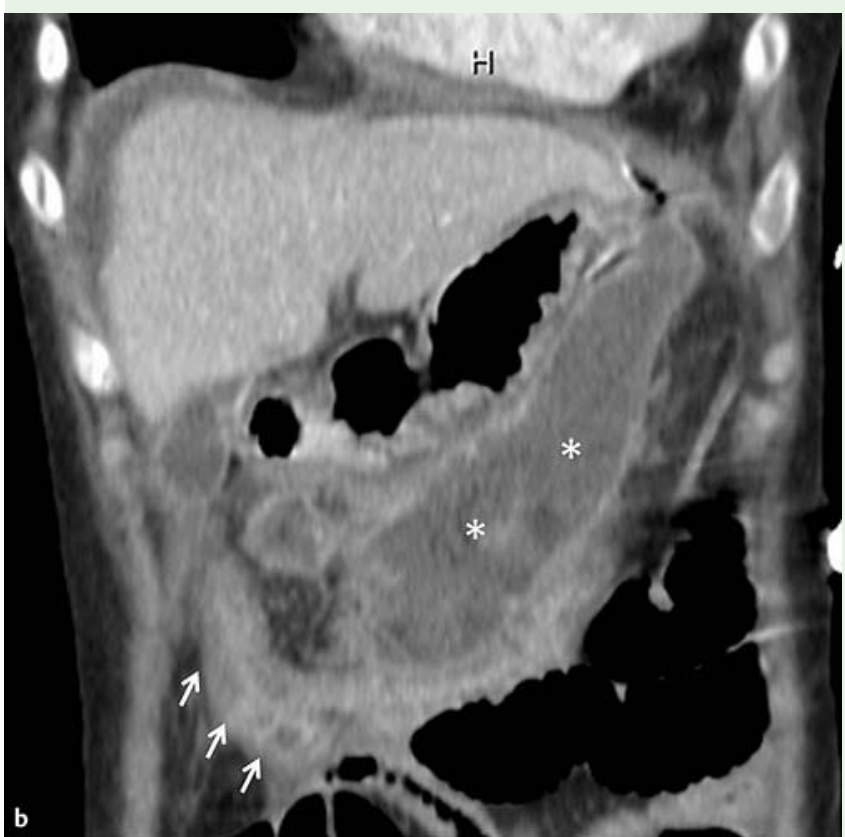

A 28-year-old woman with chronic glomerulonephritis who was treated with prednisolone for many years developed pneumonia due to Nocardia that required treatment with co-trimoxazole. She subsequently developed acute necrotizing pancreatitis and her hospital course was complicated by a prolonged fever. In the fourth week, a computed tomography (CT) scan of the abdomen to evaluate the severity of the pancreatitis demonstrated a walled-off area of pancreatic necrosis $(5 \times 6 \mathrm{~cm})$ that was extending via the transverse mesocolon to the edematous wall of the transverse colon. In addition, an air pocket was seen in the necrotic cav- ity ( Fig. 1). This raised the suspicion of infected pancreatic necrosis and/or fistula formation.

The patient developed hematochezia with hypotension 1 day later, and a colonoscopy demonstrated edema of the colonic wall on the mesenteric side of the transverse colon ( Fig. 2 a). In the edematous area, there were three indurated fistulas with necrotic material protruding through the orifices ( Fig. 2 b, c; Video 1). Unfortunately, standard debridement and drainage could not be performed because her condition deteriorated rapidly, and she died from severe bacterial and fungal sepsis.
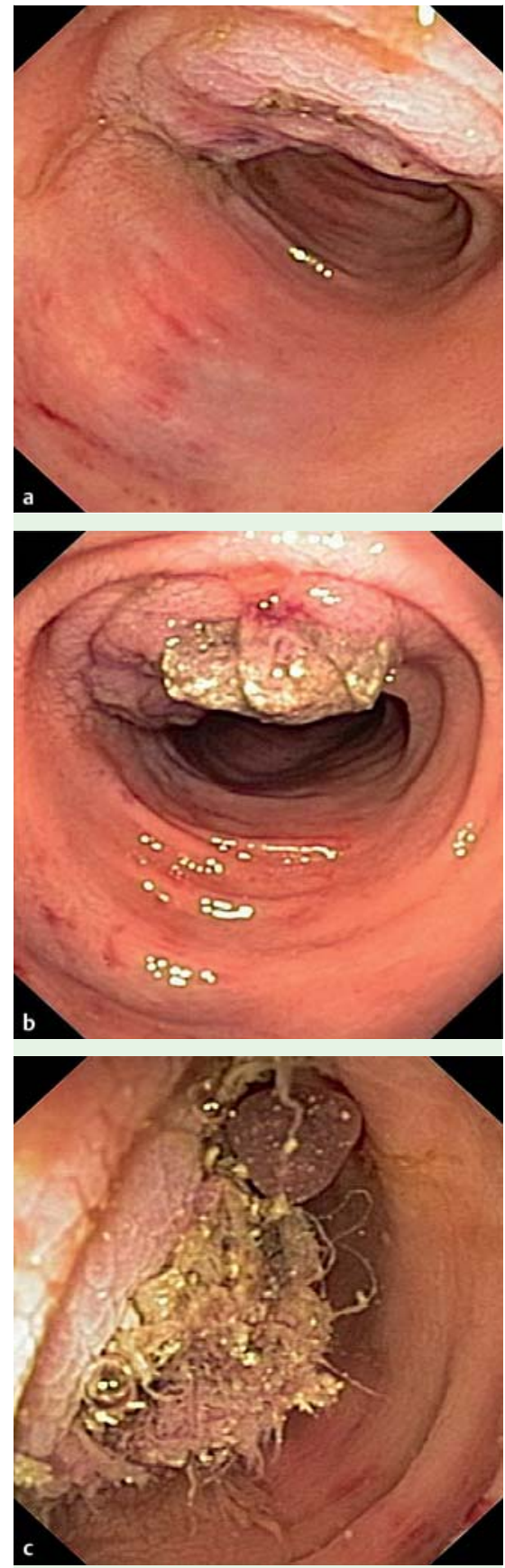

Fig. 2 Colonoscopy images showing: a the edematous wall on the mesenteric side of the transverse colon; $\mathbf{b}$ necrotic material protruding through an orifice in the edematous wall of the transverse colon; $c$ a close-up view of the necrotic material protruding through another orifice in the same area of the colon. 
Colonic involvement is an uncommon, but potentially serious, complication of severe acute pancreatitis [1-4]. The colonic complications typically range from moderate to severe and include localized ileus, obstruction from severe edema or inflammation, colonic ischemia with or without necrosis, hemorrhage, and fistula formation [1].

Colonic fistulas occur in $3 \%-10 \%$ of patients with severe acute pancreatitis [2]. An air pocket in a necrotic area of the pancreas usually indicates that infected necrosis is present and/or there is a fistula to the gastrointestinal tract. The root of the mesocolon, which is anterior to the pancreas, serves as a potential route for spread of inflammatory mediators to the colonic wall. This inflammation may lead to thrombosis of mesenteric vessels and subsequently to necrosis of the colonic

\section{Video 1}

Colonoscopic view during air insufflation showing necrotic material protruding through an orifice in the edematous wall of the transverse colon. wall [5]. The consequences of a colonic fistula may be more severe than those of fistulas at other sites because of the heavy load of multiple organisms, including fungus, present within the colon.

\section{Endoscopy_UCTN_Code_CCL_1AD_2AG}

\section{Competing interests: None}

\section{Rungsun Rerknimitr ${ }^{1}$, Narisorn Lakana- nurak', Piyapan Prueksapanich ${ }^{1}$, Sasipim Sallapant ${ }^{1}$, Phonthep Angsu- watcharakon $^{1,2}$, Pradermchai Kong- kam $^{1}$, Pinit Kullavanijaya ${ }^{1}$}

${ }^{1}$ Division of Gastroenterology, Department of Internal Medicine, Chulalongkorn University, Bangkok, Thailand

2 Department of Anatomy, Faculty of Medicine, Chulalongkorn University, Bangkok, Thailand

\section{References}

1 Mohamed SR, Siriwardena AK. Understanding the colonic complications of pancreatitis. Pancreatology 2008; 8: 153-158

2 Suzuki A, Suzuki S, Sakaguchi T et al. Colonic fistula associated with severe acute pan- creatitis: report of two cases. Surg Today 2008; 38: $178-183$

3 Ho HS, Frey CF. Gastrointestinal and pancreatic complications associated with severe pancreatitis. Arch Surg 1995; 130: 817 822 ; discussion $22-23$

4 Tsiotos GG, Smith CD, Sarr MG. Incidence and management of pancreatic and enteric fistulae after surgical management of severe necrotizing pancreatitis. Arch Surg 1995; 130: $48-52$

5 Aldridge MC, Francis ND, Glazer G et al Colonic complications of severe acute pancreatitis. Br J Surg 1989; 76: 362 - 367

Bibliography

DOI http://dx.doi.org/

10.1055/s-0033-1359134

Endoscopy 2014; 46: E30-E31

(C) Georg Thieme Verlag KG

Stuttgart · New York

ISSN 0013-726X

Corresponding author Rungsun Rerknimitr, MD

Division of Gastroenterology

Department of Internal Medicine

Faculty of Medicine

Chulalongkorn University

Bangkok 10310

Thailand

Fax: +66-2-2527839

ERCP@live.com 